Gabriele Gerda Ostkirchen

Felix Andler

Friederike Hammer

Kerstin Daniela Pöhler

Erika Snyder-Schendel

Nina Kerstin Werner

Sebastian Markett

Ulrike Horacek

Karl-Heinz Jöckel

Hans Christoph Diener

\section{Prevalences of primary headache symptoms at school-entry: a population-based epidemiological survey of preschool children in Germany}

Received: 25 April 2006

Accepted in revised form: 15 July 2006

Published online: 25 October 2006

G.G. Ostkirchen $(\varangle) \cdot$ F. Hammer

K.D. Pöhler • S. Markett • H.C. Diener

Department of Neurology, Medical Faculty,

University Duisburg - Essen,

Hufelandstraße 55,

DE-45122, Essen, Germany

e-mail: gabriele.ostkirchen@uni-essen.de

Tel.: +49-201-723-3839

Fax: +49-201-723-5822

F. Andler • E. Snyder-Schendel • N.K.

Werner • K.H. Jöckel

Institute for Medical Informatics, Biometry

and Epidemiology,

University of Essen,

Essen Germany

U. Horacek

Public Health Board,

Medical Department for Children and

Adolescents,

Recklinghausen, Germany

\author{
Abstract Primary headache and \\ functional abdominal pain preva- \\ lences in an unselected population- \\ based sample of German preschool \\ children and their parents $(n=885)$ \\ were collected in relation to \\ health-related quality of life and \\ sociodemographic variables. The \\ pain symptoms were assessed \\ according to IHS classification \\ (2004) and Rome-II criteria (1999) \\ during the 2004 data census. The \\ participation rate was $62.7 \%$, with \\ an equal gender distribution. The \\ focus of this paper lies on the \\ symptom-oriented point preva- \\ lences for primary headaches of \\ preschool children: $3.6 \%$ \\ headache, $33.2 \%$ abdominal pain, \\ $48.8 \%$ headache+abdominal pain \\ and $14.4 \%$ without pain. High \\ comorbidities for pain-affected \\ children have been found. Pain
}

intensities differ significantly only for abdominal pain (one-way ANOVA $F=3,339$, df $=4 / 445$, $\left.p=0.010^{*}\right)$, not for headaches. However, recurrent headaches show a striking ratio in favour of boys (10:1). Children at preschool age have high quality-of-life measures, already influenced negatively by paediatric pain experiences (one-way ANOVA: $F=9,193$, $\left.\mathrm{df}=4 / 546, p=0.000^{* *}\right)$. Headache and abdominal pain are relevant for children's everyday life; hence, simultaneous and prospective assessment is an essential issue in public health research.

Keywords Prevalences $\cdot$ Preschool children $\cdot$ Headache $\cdot$ Abdominal pain $\cdot$ Simultaneous symptom recording $\cdot$ Quality of life

\section{Introduction}

Paediatric isolated and recurrent primary headache as well as functional abdominal pain syndromes represent multidimensionally interfering aversive body processes [1], being influenced by closely interconnected biopsychosocial variables that are mutually dependent on each other. At present, there is little knowledge about the multiple interactions between the eligible variables in the course of development. Longitudinal prospective studies are urgently needed to identify variables that contribute to long-lasting headache or abdominal pain syndromes in children.

Primary headache and abdominal pain belong to the class of pain syndromes that are difficult to be identified through well defined pathophysiological processes. However, recurrent headache and abdominal pain without organic reasons are the most common pain symptoms in children [2-12]. A high comorbidity between these two aversive syndromes is reported $[6,13]$, which seems to continuously increase over 
time $[2,6,7,14]$. While abdominal pain symptoms tend to be more frequent, recurrent headache symptoms lead to a considerably higher impact on social activities (friends, school, sports) and to more intense disturbances of children's well-being [6, 7, 15-19] and quality of life [20-24].

Pain symptoms like those investigated in the present study are diagnosed - within the tradition of medical clinical practice - on the basis of a multitude of well examined cases, using the knowledge of an extensive number of international epidemiological studies and via informed consensus among international leading medical specialists. Nevertheless there are many recognised problems within the diagnostic process. The 2004 IHS classification for headaches [25] and the ROME-II criteria for abdominal pain [26], to be revised as Rome-III in 2006, are widely accepted but also criticised examples [27-30]. When reimplementing resulting descriptive classification rules to clinical practice, the paediatrist, for example, in his attempt to diagnose the observed pain symptoms of a certain child at a given time, meets problems, which have been described earlier [8, 11, 28, 30-32]. Additionally, results from epidemiological studies of headache and abdominal pain vary not only due to differences between study populations, methods, diagnostic criteria and their interpretations, but also because pain symptoms show extremely diverse interindividual variations over time [27-34]. According to Sillanpää and Abu-Arafeh [11], problems in defining and classifying primary headache in children proliferate because the clinical phenomenology is not always clear enough and sometimes overlaps. This statement is also true for functional abdominal pain in children. When revising the literature, Özge [8] reported published prevalences for headaches among schoolchildren from 5.9\% to $82 \%$. Further, different authors only found e.g., a poor agreement between headache frequency and intensity reported retrospectively in questionnaires and interviews compared with continuously registered data from diaries [27, 35, 36]. Also, the source of information plays an important role and contributes to the wide range of published results. In line with this, co-occurrences of different pains have been frequently observed [37] and it has often been empirically documented that children with headache report other pains more often than those without headache [16].

With respect to the above-described difficulties, the appendix of the International Classification of Headache Disorders, 2nd edition (ICHD-IIA) already allows alternative sets of diagnostic criteria for certain primary headache diagnoses that are known to be, as yet, insufficiently validated. The aim of a recently published article [30] was to compare the power of different classification systems (clinical diagnosis, ICHD-I, ICHD-II, ICHD-IIA $[25,38]$ using the expert opinion as the gold standard) when retrospectively rediagnosing 260 children treated in two headache centres assuming that "the criteria were not changed to allow these exceptions, but rather introduced with the assumption that further investigation was needed before these could be adopted" [30].

As this fact applies especially to the classification of paediatric headaches, the aim of our study is to describe in

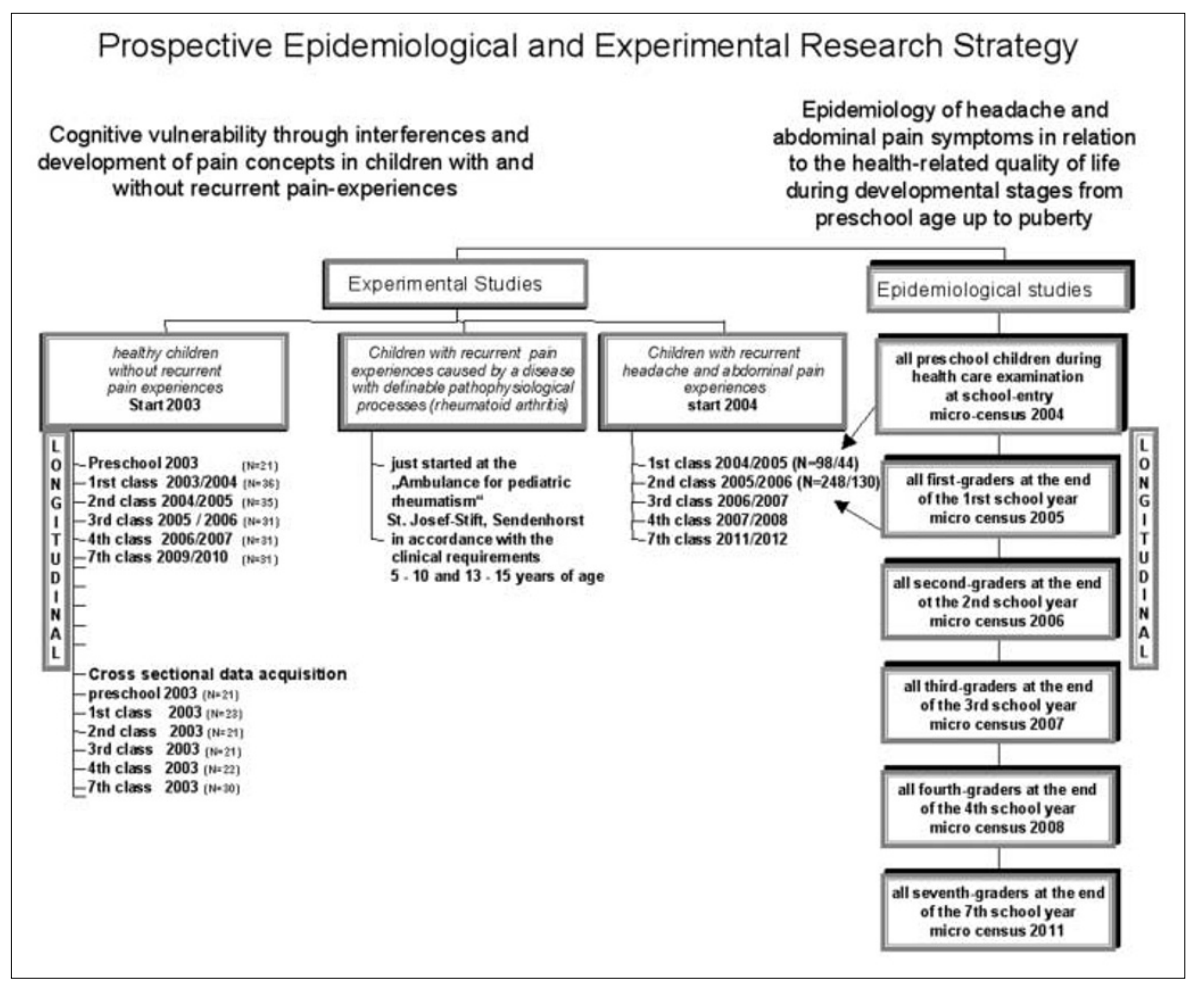

Fig. 1 The research strategy of the project 
detail prevalences of primary headache and functional abdominal pain symptoms prospectively in a populationbased sample starting at preschool age (first data-census 2004). The definition of categories of pain symptoms used based on the official medical classifications [25, 26] allows exhaustive information retrieval for each category of the defined pain symptoms and the assessment of medical and sociodemographic variables in combination with lifequality measures by starting at preschool age and using two sources of information. This procedure was chosen with the intention of finding risk-enhancing, triggering, maintaining and protective coherences in the developmental course. To attain these goals, a cross-sectional, as well as a longitudinal, prospective research strategy was implemented (Fig. 1).

A further advantage of the present study is the combination of epidemiological and experimental procedures, which enables the direct incorporation of behavioural data in the complex analyses. For the first time headache and abdominal pain symptoms were collected, in at least two senses, "simultaneously": two pain syndromes at the same time $<$ headache + abdominal pain $>$ from two sources of information $<$ parents + children $>$, to strive for the purpose of the project's intention. In this article the focus lies on the prevalences of headache symptoms in the different pain groups (headache, abdominal pain, headache+abdominal pain, no pain). In addition the occurrences of headache in family/friends as well as comorbidities, headache intensities and their influence on life-quality measures are reported for the pain groups.

All prevalences of the distinguished pain characteristics separated for children and parents can be found in Figure 3. Since children at preschool age are not able to describe the characteristics as differentiated as adults (they use more global verbal descriptors at this age), there will be a natural limitation when comparing children's and parents' results. Therefore prevalences of the distinguished pain characteristics separated for children and parents can be found in the attachment. This limit has to be considered when comparing children's results with adults' results. Another constraint of our study is that a medical examination cannot be conducted during each data census (2004, 2005, 2006, 2007, 2008, 2011). It was determined at school entry (2004) and - according to the not yet officially approved plan - there might be a possibility to repeat it at data census 4 in the 3rd class of primary school (2007).

\section{Materials and methods}

Applied material

Primary headache and abdominal pain symptoms were assessed by the self-administered questionnaire FSEKB [29] containing all symptoms mentioned in the IHS classification [25] and in the
ROME-II criteria [26] for primary headaches and functional abdominal pain in children. Presuming the child stated headache and/or abdominal pain, the parents were asked to fill out the questions covering each pain symptom exhaustively with all possible categories. For the children of the 2004 micro census still being too young to differentiate in this way - more global categories were used. At this age level a direct comparison between parents' and children's judgements seemed to be meaningful only for the global indices. The socio-demographic variables have been taken over by the German Children Youth Survey [10] and life-quality measures for 6 life areas were assessed by Kiddy-KINDL [23].

In order to describe the social demographic variables, the social class index, calculated according to Winkler [39] by using the variables 'income', 'education' and 'profession', was applied. This index was slightly modified, allowing the separate incorporation of father's and mother's data for couples. This procedure seemed to be adequate for the situation of modern families.

The ethics committee of the University Clinics in Essen reviewed this study and approved it in accordance with the ethical standards of the 1964 Declaration of Helsinki. The official supervisory school authority recommended the participation of all primary schools in the town selected. The directors of the schools, the parents and the children gave their informed written consent to participate.

\section{Data acquisition}

The first cross-sectional data census of all preschoolers of a German town (inhabitants 80 863: 39438 men; 41425 women) was enforced from the middle of January until the end of September 2004 during the official health-care examination before entering school.

\section{Statistical analysis}

Statistical analyses (like frequencies, crosstabs, Kruskal-Wallis tests, one-way ANOVA, correlations) were performed by means of SPSS software (version 13, Chicago, IL, USA). Point prevalences were calculated according to Trampisch et al. [40].

\section{Results}

\section{Subjects}

An unselected population-based sample of preschool children (according to the official report 885 school-beginners, $54.0 \%$ boys and $46.0 \%$ girls, aged on average $6.0 \pm 0.251$ years $)$ and their parents $(94.8 \%$ Germans, $5.2 \%$ foreign nationals; mean ages of mothers $35.3 \pm 4.97$ and of fathers 37.9 \pm 5.56 years) answered the FSEKB question- 
naire [29]. In $23.3 \%$ the parents refused participation and $14.1 \%$ of the parents declined in spite of at least 3 official invitations. The remaining 555 children $(=62.7 \%$ : $62.6 \%$ boys, $45.2 \%$ girls, 5-7 years old) and their parents participated. Out of 555 parents, $7.8 \%$ belonged - according to this revised Winkler's index - to the lower, $40.4 \%$ to the middle and $24.6 \%$ to the upper class. Due to missing values, a social class index could not be calculated for $27.3 \%$ of the families.

Figure 2 (a-c) shows the distribution in the different pain groups (headache $n=20$, abdominal pain $n=177$, combination of headache+abdominal pain $n=271$, no pain $n=87$ ). Further calculations can be based on an equal distribution of the gender parameters $\left(n=885, x^{2}=0.296\right.$, $\left.\mathrm{df}=2, p=0.862 ; n=555, x^{2}=0.028, \mathrm{df}=2, p=0.986\right)$.
All reported results and calculated prevalences are based on or refer to the number of participating children and parents $(n=555,100.0 \%)$, if not mentioned otherwise.

Main prevalences of primary headache and abdominal pain in preschool children (Fig. 3)

A percentage of 48.8 of the children suffer from headache combined with abdominal pain, $31.9 \%$ from abdominal pain, $3.6 \%$ have headaches and $14.4 \%$ have none of the pain entities in question. The children agree largely with their parents' judgements (Pearson correlation between the global judgements $r=0.824, p=0.003 * *)$. Overall there

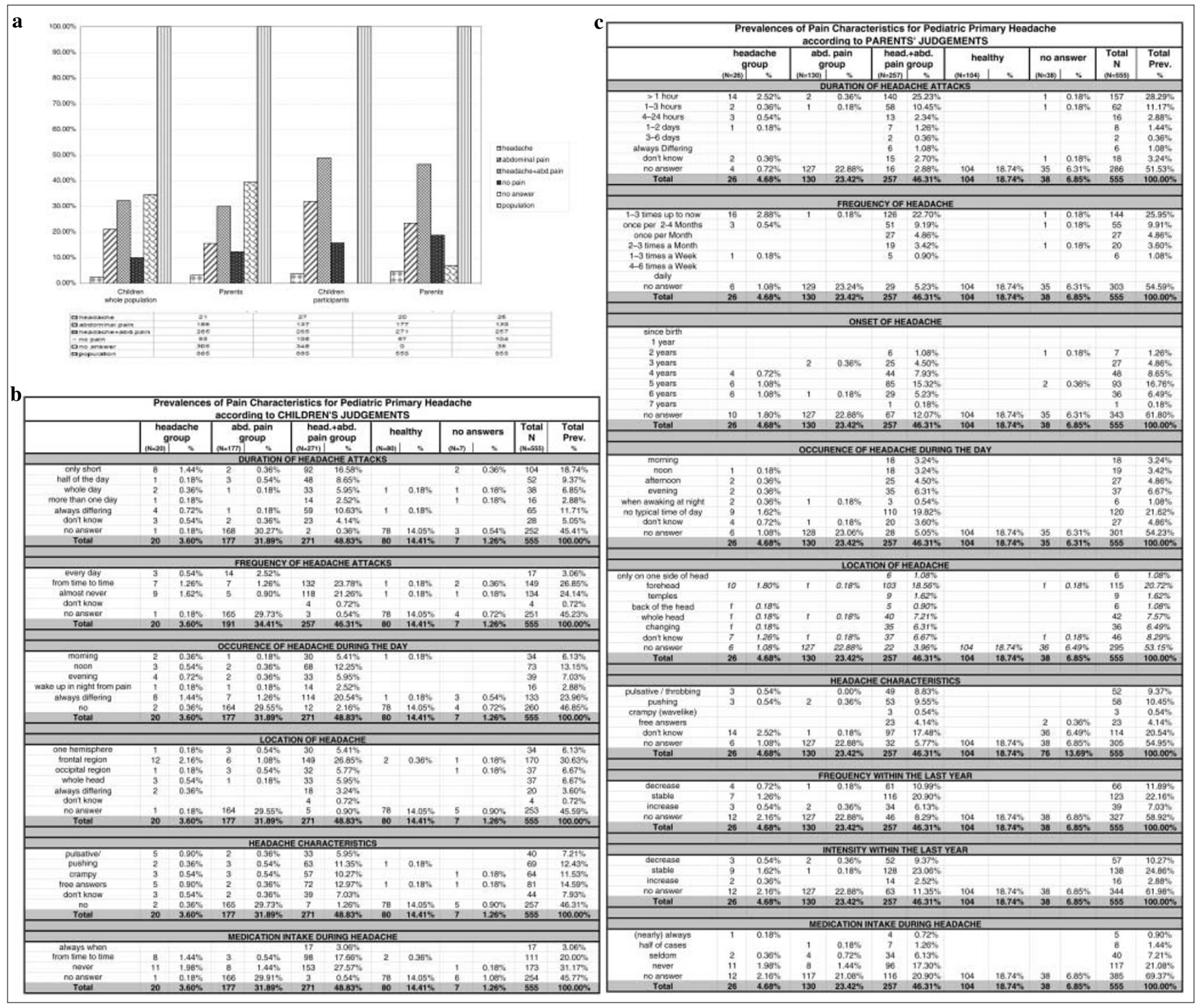

Fig. 2 a The samples examined at the first micro census in 2004. b Prevalences of headache characteristics according to children's judgements. $\mathbf{c}$ Prevalences of headache characteristics according to parent's judgements 


\begin{tabular}{|c|c|c|c|c|c|c|c|c|}
\hline \multicolumn{7}{|c|}{ Main Point Prevalences for Headache and Abdominal Pain in Preschool-Children } \\
\hline \multirow{2}{*}{$\begin{array}{c}\mathrm{N}=\mathbf{5 5 5} \\
\mathbf{1 0 0 , 0 0 \%}\end{array}$} & \multicolumn{2}{|c|}{ Headache } & \multicolumn{2}{c|}{ Abdominal Pain } & Headache\&Abd.Pain & \multicolumn{2}{c|}{ no Pain/ no answer } \\
\cline { 2 - 9 } & frequency & Prevalence & frequency & prevalence & frequency & prevalence & frequency & prevalence \\
\hline $\begin{array}{c}\text { Children's } \\
\text { judgement }\end{array}$ & 20 & & 177 & & 271 & & $80 / 7$ & \\
\hline $\begin{array}{c}\text { Parents' } \\
\text { judgement }\end{array}$ & 26 & $3.6 \%$ & & $31.9 \%$ & & $48.8 \%$ & & $14.4 \% / 1.3 \%$ \\
\cline { 2 - 9 } & & $4.7 \%$ & 130 & & 257 & & $104 / 38$ & \\
\hline
\end{tabular}

Fig. 3 Point prevalences for headache and abdominal pain in preschool children (according to children's and parents' judgements) are no statistically significant differences caused by gender at preschool age either in children's judgements (mean ranks boys 279.73/girls 268.12, $U=35598, p=0.352$ ) or parents' judgements (mean ranks boys 253.18/girls 265.98, $U=31494, p=0.294$ ). Surprisingly, highly frequent recurrent headaches show a striking boy/girl ratio of 10:1 $\left(x^{2}=11.696, \mathrm{df}=1, p=0.001^{* *}\right)$. No influence of social class index on the headache symptoms can be stated.

A complete overview of the prevalences of all headache characteristics in the different pain groups can be found in Figure 2. The following section deals with a few comments on some striking headache prevalences [index by prevalence for headache symptoms according to children's (c) and parents' (p) judgements]: (c) 45.4\%, $<>$ (p) $51.5 \%$ of the children and parents did not answer the question concerning the duration of experienced headache attacks. Pain attacks $\leq 1 \mathrm{~h}$ have a prevalence of $18.7 \%<>28.3 \%$.

While daily pain attacks (frequency of headache) are reported by children with a prevalence of $3.1 \%<>0.0 \%$ for headaches, this item is dramatically underestimated by the parents. The pain is felt for most of the children "from time to time" with a prevalence for the children of $26.5 \%$. Parents answered the more detailed items as follows: 1-3 times up to now $25.9 \%$; once per $2-4$ months $9.9 \%$; once a month $4.9 \%$; 2-3 times a month $3.6 \%, 1-3$ times a week $1.1 \%, 4-6$ times a week $0.0 \%$, daily $0.0 \%$.

The onset of headache is " 2 years" of age with a prevalence of $1.1 \%$ amounting to $14.6 \%$ until start of kindergarten with 4 years of age and $37.7 \%$ at school entry according to parents' judgements.

A percentage of $2.9<>1.1$ of the children suffering from headaches woke up during the night because of the pain (occurrence of headache during the day).

When asked for the location of the headache, most of the children feel it in the forehead $(30.5 \%<>20.5 \%)$.

The characteristics of the paediatric headache are described as crampy/wavelike in $11.4 \%<>0.5 \%$, pushing in $12.4 \%<>10.5 \%$ and pulsative/throbbing in $7.2 \%<>9.4 \%$.

Parents stated that within the last year before the 2004 micro census the frequency for headache was stable, with a prevalence of $22.2 \%$ and that it decreased in $11.9 \%$ the cases. An increase of the headache symptoms had to be stated with a prevalence of $7.0 \%$.
A percentage of $3.1<>0.9$ of the children with headache took medication each time the pain occurred, while $20.0 \%<>8.7 \%$ took medication from time to time.

Upon questioning, parents saw a rise in the pain intensities of their child within the last year of $2.9 \%$, a decrease in $10.3 \%$ and stability in $24.9 \%$ of the cases.

\section{Occurrences of headaches in family/friends}

A percentage of 94.8 of the children indicated they knew at least one person out of their familiar surroundings suffering from headache or abdominal pain. $86.8 \%$ of the parents answered this question comparably to the children. Children named 722 and adults 479 persons. Building an affection quotient by dividing the number of nominations in a pain group by the number of children in that pain group, it can be underlined that children with headache and/or abdominal pain are more intensely confronted by learning through imitation caused by relevant other persons (ratios for "headache group" $=1.1$, for "abdominal pain group"=1.1, "for headache+abdominal pain group" $=1.6$, for "no-pain group"=0.7). Parents name less pain-affected persons than children but show the same tendencies.

Comorbidities within the last three months

In total the parents nominated 973 comorbidities for their children within the last three months: the highest frequency for abdominal pain (262 nominations) followed by headaches (184 nominations). Dividing the nominations by the number of children in the pain group, the comorbidity quotients are 2.36 for the "headache+abdominal pain group", 1.5 for the "headache group", 1.28 for the "abdominal pain group" and 0.98 for the "no pain group". Headaches and abdominal pain syndromes were the most prominent pain disturbances of the preschoolers reported by the parents.

In the last 3 months, 276 children did not experience headache, 122 children had isolated headache experiences and for 65 children recurrent headaches were described. For abdominal pain 479 valid answers were given by the par- 
ents. Isolated abdominal pain situations were experienced by 145 children, 120 children experienced this type of pain recurrently and 214 children were free from abdominal pain in the last 3 months. Before introducing the results for the quality of life, we will go into more details about the comparison of pain intensities between the defined pain groups.

Pain intensities: comparison children/parents

The intensities for headache and abdominal pain (measured on a visual analogue scale from $0 \mathrm{~mm}$ to $100 \mathrm{~mm}$ ) are shown in Figure 4. A global comparison between mean pain intensities in dependence of the pain groups showed no differences in the parents' judgements (one-way ANOVA: headache $F=0,352, \mathrm{df}=4 / 227, p=0.843$; abdominal pain $F=2,186, \mathrm{df}=4 / 320, p=0.070)$. In the children's judgements, however, a difference in the intensity for abdominal pain did occur (one-way ANOVA $F=3,389, \mathrm{df}=4 / 445, p=0.010$ ). Children suffering from both headache and abdominal pain seem to experience higher intensities for abdominal pain than children with isolated abdominal pain.

Life-quality and pain experiences in preschool children

According to parents' judgements, preschoolers achieve a high mean average quality of life index (from 72.78 to
91.88 on a scale transformed to percent ranks from $0-100$, see Figure 5). More detailed information can be taken from the table underneath the figure showing the means for each pain group over all relevant life areas.

When comparing the global LQ indices between parents and children, it becomes evident that parents deny the loss of life quality already felt by the children with

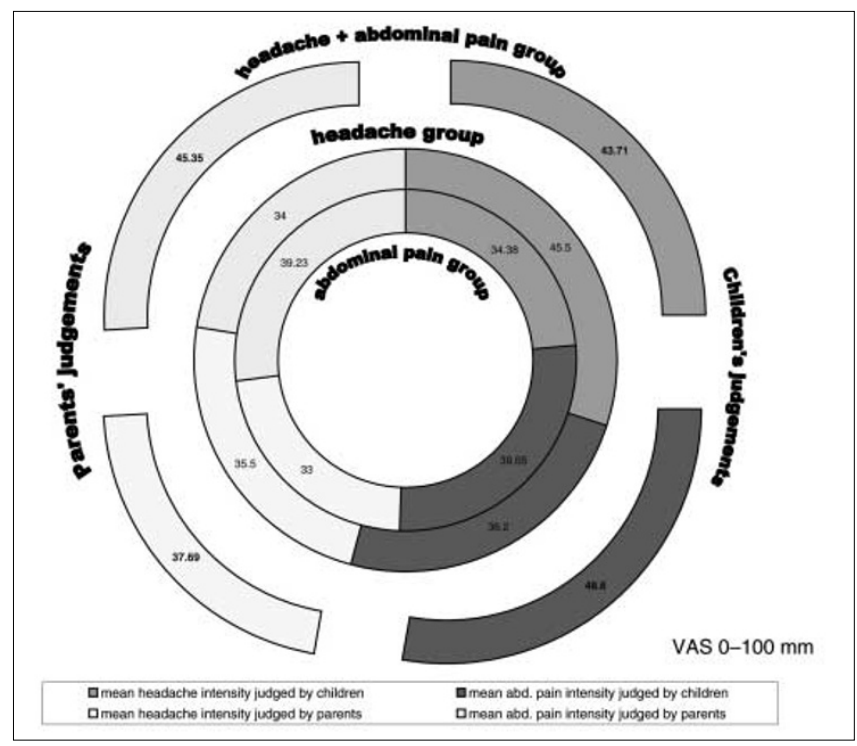

Fig. 4 Comparison of the pain intensities for headache and abdominal pain according to children's and parents' judgements. Inner circle, headache group; middle circle, abdominal pain group; outer circle, headache+abdominal pain group

\begin{tabular}{|c|c|c|c|c|c|c|}
\hline \multicolumn{1}{|c|}{} & & \\
\hline \\
triends
\end{tabular}

Fig. 5 Quality of life in 6 life areas depending on the pain groups (according to parents' judgements) 


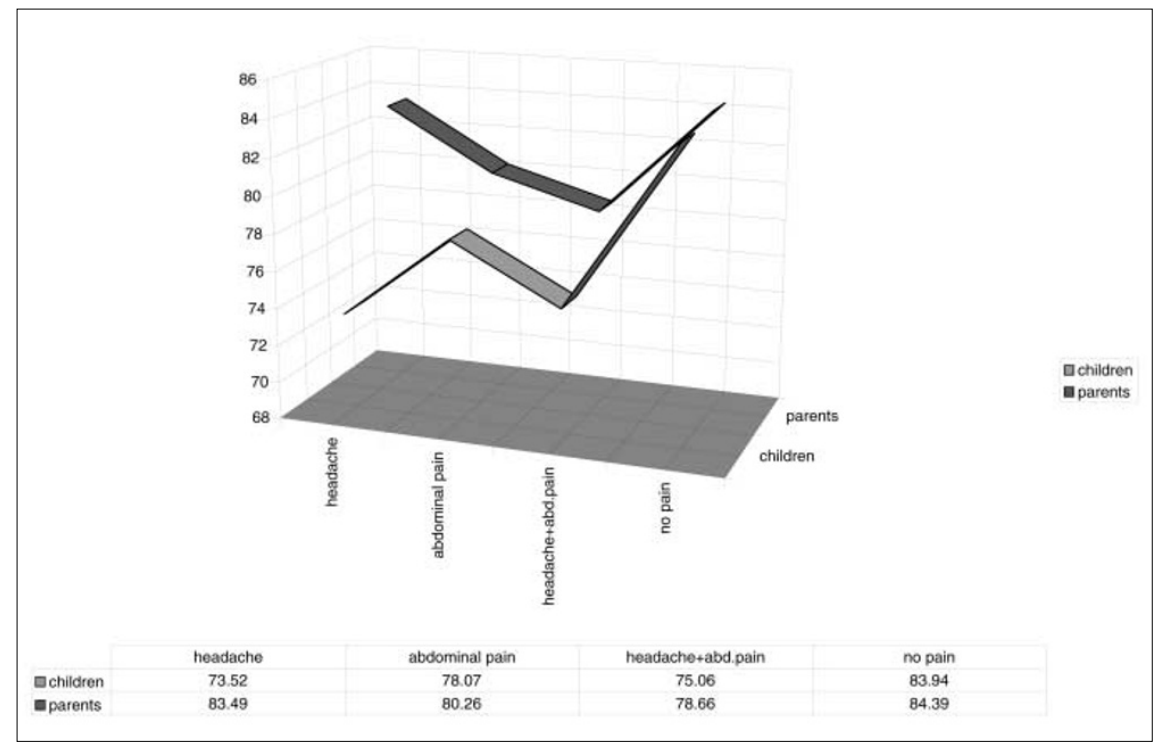

Fig. 6 Comparison of the total qualityof-life index depending on the pain groups (children's and parents' global judgements) headache and/or abdominal pain (paired $t$-test: $t=4.749$, $\mathrm{df}=546, p=0.000$ ) (Fig. 6). Recurrent pain experiences lead already in preschool age to a significant impairment (one-way ANOVA: $F=9,193, \mathrm{df}=4, p=0.000$ ).

\section{Discussion}

During the first 2004 micro census, a participation rate of $62.7 \%$ of the whole regional sample $(n=885)$ was reached. When comparing to higher numbers reported internationally (e.g., from Finland), this cannot be judged satisfactory despite the positive circumstances, the parents being directly accessible during the official health-care examination. This will not be the case during the next four data acquisitions in 2005-2007 and in 2011 (the questionnaires are distributed via the teachers to the pupils who then bring them home to their parents), so we can expect still lower participation rates in the years to come.

In our sample headache and abdominal pain belong to the normal experiences of children's life. Only $14.4 \%$ of the participating children never experienced headache or abdominal pain. Headaches combined with abdominal pain are the most prominent pain experiences in preschool children $(48.8 \%)$, followed by isolated abdominal pain $(31.9 \%)$ and headache experiences $(3.6 \%)$.

Parents notice if their children suffer from aversive body stimuli, but they differ in the evaluation. They particularly underestimate the suffering of their preschool children from recurrent headaches and abdominal pain. Isolated abdominal pain experiences are ten times more frequent than isolated headache experiences; the prevalence increases for isolated abdominal pain events occur- ring in combination with headaches. Surprisingly preschool boys experience highly frequent recurrent headaches more often than girls of this age (boy/girl ratio 10:1). As internationally reported (e.g., Özge et al. [8]), further specific influences on pain characteristics by gender or social class have not been detected for our examined sample, being 5-6 years of age.

For the still very young participants it seems to be difficult to adequately judge the duration of the headache attacks (high ratio of indifferent answers $62.2 \%$ ); but in $2.9 \%$ of the cases the attacks last even longer than one day. An attack duration that is shorter than one hour was found for $18.7 \%$ of the participating children. This period is overestimated by the parents $(28.3 \%)$, who underestimate at the same time that their siblings suffer in $19 \%$ of the cases longer than half a day from these attacks.

When focussing on the frequency of headache attacks, the tendency of the parents to underestimate the suffering of their children becomes still more apparent. While $3.1 \%$ of the children inform that they suffer daily from headache attacks, none of the parents report this. While children in $26.9 \%$ of the cases experience these aversive body sensations from time to time, $9.9 \%$ of parents notice it once per 2-4 months and to $9.5 \%$ notice it weekly/monthly. Although the suffering from headache is underestimated, the parents are aware of this problem.

Parents call attention to the fact that already at the age of 2 years their babies experienced headaches in $2.2 \%$ of the cases. This percentage is increasing over time, reaching $14.6 \%$ at the age of 4 years and $37.7 \%$ at school entry. This sharp rise of the onset prevalences of headaches shows how urgent it is to focus on these pain problems already in the developmental course. 
While $23.9 \%$ of the children are not able to tell at what time of day the headaches occur, because the start is not fixed to a specific time, $6.1 \%$ of the children experience headaches in the morning, $13.2 \%$ in the afternoon and $7 \%$ in the evening. Young children (2.9\%) experience headaches even at night and describe being awoken by this pain. Parents obviously underestimate this problem of nocturnal headache experiences. It is possible that the children forget to tell their parents about these night disturbances.

A percentage of 30.6 of the preschool children point to the frontal region when being asked to locate the experienced headaches: $6.1 \%$ describe their headache as onesides, $6.7 \%$ say the whole head is afflicted and $6.7 \%$ say headache occurs in the occipital region. For $3.6 \%$ of the cases the location of headache is always differing. The affliction of only one side of the head was named in $6.1 \%$ of the cases by the children, but only in $1.9 \%$ according to parents' judgements. This may underline that it is better to ask the person experiencing the headache directly, as is common practice for adults.

Already a prevalence of $3.6 \%$ of the children report medication intake each time the pain occurs; and 20\% take medication from time to time. Parents are more conservative when answering this question. Only in $0.9 \%$ of the cases do they admit to giving medication each time and in $8.7 \%$ from time to time when the child complains of headaches. However, in $69.4 \%$ of the cases this question was not answered.

Regarding the changes in headache frequency/intensity over the last year, parents reported a decrease in $11.9 \% / 10.3 \%$ of the cases, the aversive experiences of the child remained stable in $22.2 \% / 24.9 \%$ and an increase in $7 \% / 2.9 \%$.

The assumption that children with headache-affected family members have a higher probability of experiencing headaches themselves can be accepted - with an affection quotient of the pain groups ranging from 1.1 to 1.6 and for the no-pain group amounting to 0.7 .

The same is the case when comparing the named comorbidities within the last three months in the pain groups. The highest comorbidity rate is found for children suffering from headaches combined with abdominal pain, followed by the headache group and then by the abdominal pain group. The same order seems to be found for pain intensities - judged by the children themselves - where children experiencing combined headache and abdominal pain reach higher headache intensity levels than the group's pain intensities concentrating on one body region. The biggest discrepancies, of about $10 \mathrm{~mm}$, between parents' and children's judgements of the pain intensities can be found for the headache group. Children are much more affected by headaches than their parents think. As mentioned before, there is considerably higher impact through comorbidities for the pain groups than for the no-pain group and in line with these finding a considerable impact can be found on the life-quality index, despite the fact that preschool children as a whole present high quality-of-life measures over all life areas.

\section{Conclusions}

The simultaneous assessment of primary headache and abdominal pain symptoms in an unselected populationbased preschool sample is new and proved to be an essential matter to public health research. Children of this age already suffer from headaches and abdominal pain experiences. Both types of pain experiences are relevant for children's everyday life. They contribute to an increase of vulnerability. To follow the course of development of pain experiences and to systematically consider them in context with sociodemographic and life-quality measures over school-time seems to be a promising research strategy.

Acknowledgements We thank all participants (schools, teachers, parents and especially the children, as well as the doctoral candidates) for their unique contribution to our study. Special thanks go to the Chairman of the Neurological Clinics, Prof. Dr. H.C. Diener, for his continuous encouragement and support, which substantially made this study possible.

\section{References}

1. Mühlig S, Petermann F (1997)

Idiopathischer Bauchschmerz im

Kindesalter. Ergebnisse, Defizite und

Perspektiven empirischer Forschung.

Der Schmerz 11:148-157

2. Abu-Arafeh I (ed) (2002) Childhood headache. Clinics in developmental medicine; 158. MacKeith Press, London
3. Aromaa M, Sillanpää ML, Rautava $P$, Helenius H (1998) Childhood headache at school entry: a controlled clinical study. Neurology 50:1729-1736

4. Brattberg G (1994) The incidence of back pain and headache among Swedish school children. Qual Life Res 3[Suppl I]:27-31
5. Guidetti V, Galli F (1998) Evolution of headache in childhood and adolescence: an 8-year follow-up. Cephalalgia 18: 449-454

6. Krämer D (2004) Idiopathischer Bauchschmerz im Kindesalter: Identifikation ätiologischer Einflüsse und Entwicklung einer Intervention. University Dortmund 
7. Kröner-Herwig B, Morris L, Heinrich M (2005) Die Epidemiologie des Kopfschmerzes im Kindes- und Jugendalter: Ergebnisse einer populationsbasierten Studie. 10. Kongress der Deutschen Gesellschaft für

Verhaltensmedizin und

Verhaltensmodifikation. DGVM, München

8. Özge A, Bugdayci R, Sasmaz T et al (2003) The sensitivity and specificity of the case definition criteria in diagnosis of headache: a school-based epidemiological study of 5562 children in Mersin. Cephalalgia 23:138-145

9. Roth-Isigkeit A, Thyen U, Raspe HH et al (2004) Reports of pain among German children and adolescents: an epidemiological study. Acta Paediatr 93:258-263

10. Schubert I, Horch K et al (2004) Schwerpunktbericht der Gesundheitsberichterstattung des Bundes: Gesundheit von Kindern und Jugendlichen. Robert-Koch-Institut, Berlin

11. Sillanpää M, Abu-Arafeh I (2002) Epidemiology of recurrent headache in children. In: Abu-Arafeh I (ed) Childhood headache. Clinics in developmental medicine No. 158. MacKeith Press, London, pp 19-34

12. Virtanen R, Aromaa M, Rautava $P$ et al (2002) Changes in headache prevalence between pre-school and prepubertal ages. Cephalalgia 22:179-185

13. Laurell K, Larsson B, Eeg-Olofsson O (2005) Headache in schoolchildren: association with other pain, family history and psychosocial factors. Pain 119:150-158

14. Guidetti V, Galli F, Cerutti R, Fabrizi P (2000) Chronic daily headache in developmental ages: diagnostic issues. J Headache Pain 1[Suppl 1]:89-94

15. Bode G, Brenner H, Adler G, Rothenbacher D (2003) Recurrent abdominal pain in children: evidence from a population-based study that social and familial factors play a major role but not Helicobacter pylori infection. J Psychosom Res 54:417-421

16. Grohold EK, Stigum H, Nordhagen R, Kohler L (2003) Recurrent pain in children, socio-economic factors and accumulation in families. Eur $\mathbf{J}$ Epidemiol 18:965-975
17. Palermo TM (2000) Impact of recurrent and chronic pain on child and family daily functioning: a critical review of literature. J Dev Behav Pediatr 21:58-69

18. Passchier J, Orlebeke JF (1985) Headaches and stress in schoolchildren: an epidemiological study. Cephalalgia 5:167-176

19. Stewart WF, Scher AI, Lipton RB (2001) Stressful life events and risk of chronic daily headache: results from the frequent headache epidemiology study. Cephalalgia 21:278-280

20. Bandell-Hoekstra IE, Abu-Saad HH, Passchier J et al (2002) Coping and quality of life in relation to headache in Dutch schoolchildren. Eur J Pain 6:315-321

21. Bullinger M, Mackensen S, Kirchberger I (1994) KINDL ein Fragebogen zur gesundheitsbezogenen Lebensqualität von Kindern. Z Gesundheitspsychologie 2:64-67

22. Frare M, Axia G, Battistella PA (2002) Quality of life, coping strategies, and family routines in children with headache. Headache 42:953-962

23. Ravens-Sieberer U (1994) Verfahren zur Erfassung der gesundheitsbezogenen Lebensqualität bei Kindern und Jugendlichen - Ein Überblick. Bundesgesundheitsblatt. Gesundheitsforschung 42:198-209

24. Ravens-Sieberer U, Cieza A (ed) (2000) Lebensqualität und Gesundheitsökonomie in der Medizin - Konzepte, Methoden, Anwendung. Ecomed-Verlag, München

25. Headache Classification, Subcommittee of the International Headache Society (2004) The International Classification of Headache Disorders, 2nd edn. Cephalalgia 24:1

26. Douglas A, Drossman MD with the Rome Multinational working Teams (1999) Rome II. Diagnostic Criteria for the functional Gastrointestinal Disorders. Gut 4:16-26

27. Laurell K, Larsson B, Eeg-Olofsson O (2003) Headache in school-children: agreement between different sources of information. Cephalalgia $23: 420-428$
28. Olesen J, Rasmussen BK (1996) The International Headache Society classification of chronic daily and near-daily headaches: a critique of the criticism. Cephalalgia 16:407-411

29. Ostkirchen GG, Andler F (2004) Simultaneous symptom recording of primary headache and functional abdominal pain in nursery children. Poster presented at the European Headache Federation (EHF) 7th Headache Congress, Rotterdam, the Netherlands, 16-19 June

30. Hershey A, Winner P, Kabbouche MA et al (2005) Use of the ICHD-II criteria in the diagnosis of pediatric migraine. Headache 45:1288-1297

31. Winner P, Wasiewski W, Gladstein J, Linder S (1997) Multicenter prospective evaluation of proposed pediatric migraine revisions to the IHS criteria. Pediatric Headache Committee of the American Association for the Study of Headache. Headache 37:545-548

32. Zebenholzer K, Wöber C, Kienbacher C, Wöber-Bingöl C (2000)

Migrainous disorder and headache of the tension-type not fulfilling the criteria: a follow-up study in children and adolescents. Cephalalgia 20:611-616

33. Rasquin-Weber A, Hyman PE, Cucchiara S et al (1999) Childhood functional gastrointestinal disorders. Gut 45[Suppl II]:1160-1168

34. Wöber-Bingöl C, Wöber C, WagnerEnnsgraber C et al (1996) IHS criteria for migraine and tension-type headache in children and adolescents. Headache 36:231-238

35. Methsähonkala JH, Sillanpää M, Tuominen J (1997) Headache diary in the diagnosis of childhood migraine. Headache 37:240-244

36. Van den Brink M, Bandell-Hoekstra ENG, Huijer Abu-Saad H (2001) The occurrence of recall bias in pediatric headache: a comparison of questionnaire and diary data. Headache 41:11-20

37. Kristjansdottir G (1997) Prevalence of pain combinations and overall pain: a study of headache, stomach pain and back pain among schoolchildren. Scand J Soc Med 25:58-63 
38. Headache Classification Committee of the International Headache Society (1988) Classification and diagnostic criteria for headache disorders, cranial neuralgias and facial pain. Cephalalgia 8[Suppl 7]:1-96
39. Winkler J (1998) Die Messung des sozialen Status mit Hilfe eines Index in den Gesundheitssurveys der DHP. In: Ahrens W, Bellach BM, Jöckel KH (eds) Messung soziodemographischer Merkmale in der Epidemiologie. Schriften des Robert Koch-Institutes, München 1/98, pp 69-74
40. Trampisch HJ, Windeler J, Ehle B, Lange S (1997) Maßzahlen für Krankheitshäufigkeiten. In Trampisch HJ, Windeler J (eds) Medizinische Statistik. Springer-Verlag, Berlin, Heidelberg, pp 86-96 